\title{
Double-chambered Right Ventricle in Children
}

\author{
Shi-Min Yuan \\ The First Hospital of Putian, Teaching Hospital, Fujian Medical University, Fujian Province, People's Republic of China
}

\begin{abstract}
A double-chambered right ventricle (DCRV) is a rare congenital heart defect. The clinical features of DCRV, especially in the pediatric population, have not been sufficiently elaborated. There are many unanswered questions regarding the surgical indications, surgical timing, natural history, and patient outcomes. This article will discuss the definition, pathophysiology, clinical features and treatment of DCRV. This systematic review showed a higher prevalence of symptomatic patients among children with DCRV with signs of right ventricular pressure overload and associated congenital heart defects. The spatial relation between ventricular septal defect and the anomalous muscle bundle might be a determinant of right ventricular obstruction. Symptomatic patients with an intra-right ventricular pressure gradient of $>20 \mathrm{mmHg}$ are indicated for a surgical repair. DCRV has a favourable postoperative course as no postoperative death was reported. Mechanisms of right ventricular obstruction warrant further elucidations based on larger patient population in the near future.
\end{abstract}

Key Words: Cardiac surgical procedures, Heart defects, Congenital, Heart ventricles.

How to cite this article: Yuan SM. Double-chambered right ventricle in children. J Coll Physicians Surg Pak 2019; 29(12):1193-1198.

\section{INTRODUCTION}

A double-chambered right ventricle (DCRV) is a rare congenital condition in which the right ventricle is divided into a proximal high-pressure chamber and a distal lowpressure chamber by abnormal muscle bundles. ${ }^{1}$ In such patients, right ventricular outflow tract obstruction often develops especially in those with an abnormally short distance between the moderator bundle and pulmonary valve. ${ }^{2}$ The presence of abnormal muscle bundles can produce a pressure gradient between the inflow and outflow of the right ventricle. ${ }^{3}$ The obstruction can be progressive with time. ${ }^{4}$ Debate persists regarding the exact pathogenesis of the obstructing muscle bundles, although it was proposed that the mechanisms were hypertrophy of the moderator band arising abnormally high from the interventricular septum, and hypertrophy or displacement of the accessory septoparietal/septomarginal trabeculations. ${ }^{4}$

An isolated DCRV is very rare, representing only $6.2 \%$ of the patients, while approximately $80-90 \%$ of the DCRV cases are associated with various congenital heart defects, with ventricular septal defect (VSD), in particular a perimembranous type VSD, being the most common. According to Hoffman, the most frequent associated congenital heart defect in DCRV patients

Correspondence to: Shi-Min Yuan, Department of Cardiothoracic Surgery, The First Hospital of Putian, Teaching Hospital,

Fujian Medical University, Fujian Province, People's Republic of China

E-mail: shiminyuan@126.com

Received: March 26, 2019; Revised: July 31, 2019;

Accepted: July 31, 2019 was VSD, which accounted for $84.4 \%$, followed by membranous subaortic stenosis (31.3\%). 5 DCRV can also be an associated anomaly of Williams syndrome. 6 This anomaly is often diagnosed during childhood and adolescence, while very few were found in adults. ${ }^{7}$ However, there is no consensus on surgical indications and on the optimal timing of surgical operation in terms of the severity of obstruction and the hemodynamic burden of the right ventricle. 4

The aim of this review was to discuss the definition, pathophysiology, clinical features, and treatment of pediatric DCRV.

\section{METHODOLOGY}

The Preferred Reporting Items for Systematic Reviews and Meta-analyses (PRISMA) statement guidelines were followed in this meta-analysis. Publications were systematically searched in the PubMed, Highwire Press, and the Cochrane Library databases from January 2000 to December 2018. The MeSH terms and keywords used to identify articles included "double-chambered", "two-chambered", "right ventricle", "double chambered right ventricle (DCRV)", "anomalous muscle bundles", and "hypertrophied moderator band", with a filter of "pediatrics". The screening of the bibliographic references helped in completing the literature retrieval. Forty-two articles were found related to the topic and keywords in the literature search; and 18 articles, which met the inclusion and exclusion criteria during preliminary assessment, were included in the review. The exclusion criteria were articles of double-chambered left ventricle $(n=7)$, DCRV of adult patients $(n=5)$, no substantial information of pediatric DCRV patients $(n=4)$, pediatric 
patient information unable to be sorted out from that of adult patients $(n=2)$, pediatric patient with a previous history of DCRV repair $(n=1)$, and being irrelevant to pediatric DCRV $(n=5)$.

The data independently extracted from each study were the study population, demographics, clinical manifestations, diagnostic techniques, pre- and postoperative intra-right ventricular pressure gradients, associated disorders, conditions of the infundibulum, anomalous muscle bundles, therapeutic strategies, and patient outcomes.

The measurement data were expressed in mean \pm standard deviation, and were compared by independent sample/ paired t-test. The categorical variables were presented as frequency and percentage, and were compared by Fisher exact test. $p<0.05$ was considered statistically significant. An IBM SPSS statistics version 22.0 was used to perform the statistical analyses.

\section{RESULTS}

In total, 18 articles reporting pediatric DCRV were collected, ,4,8-24 with 3 original articles, 4,8,15 1 case series; 18 and 14 case reports included. $9-14,16,17,19-24$ As a result, as many as 62 pediatric patients were recruited in this study. One of the patients was a fetus, who was diagnosed with DCRV and also delivered at 28-week gestation, and died at the age of 6 hours. This case was approximately regarded as at an age of 0 . Thus, patients of this setting were at a mean age of $10.4 \pm 5.2$ years $(n=18)$. The gender of 38 patients was known: $18(47.4 \%)$ were males and $20(52.6 \%)$ were females $\left(\chi^{2}=0.2, p=0.819\right)$. There was no age difference between male and female patients $(13.0 \pm 3.7$ years vs. $11.4 \pm 5.8$ years, $p=0.551)$.

Clinical manifestations were described for $20(20 / 62$, $32.3 \%)$ patients, who had 28 symptoms. Three (10.7\%) patients were asymptomatic, and $25(89.3 \%)$ were symptomatic $\left(\chi^{2}=34.6, p<0.001\right)$. Of the symptomatic patients, dyspnea/shortness of breath was the most common presenting symptoms (Table I).

A heart murmur was audible in $10(10 / 62,16.1 \%)$ patients. In one patient, the heart murmur was unspecified. 16 Of the remaining 9 patients, all had one or more systolic murmurs. The heart murmur was audible at the left sternal boarder in 4 (44.4\%) patients, $9,13,14,17$ at the right sternal boarder in $3(33.3 \%)$ patients, $10,22,24$ and at precordium $^{20}$ and at all foci12 in $1(11.1 \%)$ patient, respectively.

Among 6 patients with an electrocardiogram examined, $2(33.3 \%)$ patients had sinus tarchycardia,9,13 1 (16.7\%) patient had normal sinus rhythm, ${ }^{22}$ and $3(50 \%)$ patients showed signs of left/right ventricular hypertrophy or left atrial enlargement. 10,12,14

The locations/natures of the hypertrophied anomalous muscle bands were heterogeneously described for 30 patients (Table II).
An intra-right ventricle pressure gradient was measured by echocardiography in 51 (51/62, 82.3\%) patients,4,8-17,20,23,24 and by catheterisation in $27(27 / 62,43.5 \%)$ patients, $4,8,15$ with a mean pressure gradient of $92.8 \pm 27.6$ (rang, 45-141; median, 86) $\mathrm{mmHg}(\mathrm{n}=17)$.

The infundibulum of the right ventricle was described in 6 patients: it was normal in $2(33.3 \%)$ patients, ${ }^{13,14}$ and

Table I: Clinical symptoms.

\begin{tabular}{|c|c|}
\hline Symptom & $\mathrm{n}(\%)$ \\
\hline Asymptomatic $20,22,24$ & $3(10.7)$ \\
\hline Symptomatic & $25(89.3)$ \\
\hline Dyspnea/shortness of breath $4,11,16,17,23$ & $9(36)$ \\
\hline Cyanosis 4,10 & $2(8)$ \\
\hline Palpitation ${ }^{9,12}$ & $2(8)$ \\
\hline Heart failure ${ }^{9,13}$ & $2(8)$ \\
\hline Fatigue ${ }^{12,17}$ & $2(8)$ \\
\hline Cardiac arrest 21 & $1(4)$ \\
\hline Exercise intolerance $^{4}$ & $1(4)$ \\
\hline Easy fatigability 9 & $1(4)$ \\
\hline Loss of appetite ${ }^{9}$ & $1(4)$ \\
\hline Fever9 ${ }^{2}$ & $1(4)$ \\
\hline Growth retardation ${ }^{14}$ & $1(4)$ \\
\hline Hydrops fetalis ${ }^{19}$ & $1(4)$ \\
\hline Weight loss 6,9 & $1(4)$ \\
\hline
\end{tabular}

Table II: The locations / natures of the hypertrophied anomalous muscle bands.

\begin{tabular}{|c|c|}
\hline Locations/natures of anomalous muscle bands & $\mathrm{n}(\%)$ \\
\hline $\begin{array}{l}\text { Ventricular septal defect was proximal to the obstructing } \\
\text { muscle bundle }{ }^{15}\end{array}$ & $\begin{array}{c}(44.8) \\
13\end{array}$ \\
\hline Distal to the bundle 15 & $8(27.6)$ \\
\hline In the right ventricular outflow tract region 9,17 & $2(6.9)$ \\
\hline At the infundibular and right ventricular outflow tract ${ }^{11}$ & $1(3.4)$ \\
\hline At the infundibular region $1^{2}$ & $1(3.4)$ \\
\hline Hypertrophied moderator band 10 & $1(3.4)$ \\
\hline $\begin{array}{l}\text { Between the septal tricuspid valve and the anterior wall } \\
\text { of right ventricle }\end{array}$ & $1(3.4)$ \\
\hline In the roof of the right ventricular chamber ${ }^{14}$ & $1(3.4)$ \\
\hline $\begin{array}{l}\text { Between the thin-walled infundibulum and the inflow } \\
\text { segment of the right ventricle } 16\end{array}$ & $1(3.4)$ \\
\hline
\end{tabular}

Table III: 64 associated congenital cardiac disorders in 53 patients.

\begin{tabular}{|c|c|}
\hline Associated congenital cardiac disorders & $\mathrm{n}(\%)$ \\
\hline VSD & $49(76.6)$ \\
\hline VSD, perimembranous $4,9,11,15,18,23,24$ & $34(69.4)$ \\
\hline VSD, muscular 4,15 & $6(12.2)$ \\
\hline VSD, multiple, apical21 & $1(2.0)$ \\
\hline VSD, supracristal15 & $1(2.0)$ \\
\hline VSD, unspecified 8 & $7(14.3)$ \\
\hline Subaortic aortic stenosis $4.8,17$ & $6(9.4)$ \\
\hline Atrial septal defect 8,10 & $2(3.1)$ \\
\hline Pulmonary stenosis 4 & $2(3.1)$ \\
\hline Aneurysm of the membranous interventricular septum ${ }^{22}$ & $1(1.6)$ \\
\hline Aortic coactation 4 & $1(1.6)$ \\
\hline Asymmetric septal hypertrophy (IVS $2.85 \mathrm{~cm}$, with no LVOTO) 12 & $1(1.6)$ \\
\hline Dextracardia10 & $1(1.6)$ \\
\hline Right aortic arch 4 & $1(1.6)$ \\
\hline
\end{tabular}

IVS = Interventricular septum; LVOTO = Left ventricular outflow tract obstruction; $V S D=$ Ventricular septal defect 
abnormal in $4(66.7 \%)$ patients $\left(\chi^{2}=1.3, p=0.567\right)$ [including a hypertrophied anomalous muscle at the infundibular region $(n=2), 11,12$ a narrow infundibulum due to hypertrophy $(n=2), 10$ and a thin-walled infundibulum $(n=1) .16$

Ventricular hypertrophy was seen in 12 (12/62, 19.4\%) patients: it was right ventricular hypertrophy in 10 (83.3\%) patients, biventricular hypertrophy in 1 (8.3\%) patient, and biventricular hypertrophy with right atrial enlargement in $1(8.3 \%)$ patient, respectively $\left(\chi^{2}=20.3\right.$, $\mathrm{p}<0.001)$.

Nine (14.5\%) patients had an isolated DCRV, 8,13-16,18-20 and in $53(85.5 \%)$ patients, the DCRV was associated with one or more congenital heart defects $\left(\chi^{2}=62.5\right.$, $\mathrm{p}<0.001$ ).

The latter 53 patients had 64 associated congenital heart defects, with VSD being the most common (Table III). Of the patients with a VSD, the perimembranous type VSD was the most common, accounting for $81.0 \%$ (34/42) by excluding the cases with an unspecified VSD type.

Three $(4.8 \%)$ patients were complicated with infective endocarditis, 4,13 and $1(1.6 \%)$ patient presented with multiple vertebral malformations, mental retardation, microcephaly, facial dysmorphology and growth retardation. 22

The treatment of choice was reported for 20 (32.3\%) patients: $19(95 \%)$ patients were surgically treated, and $1(5 \%)$ patient was conservatively managed $\left(\chi^{2}=32.4\right.$, $\mathrm{p}<0.001)$.

Of the 19 surgically treated patients, anomalous muscle bundle resection was performed in all cases. Besides, $5(5 / 19,26.3 \%)$ patients had one or two concurrent intracardiac operations, including pulmonary valve vegetation excision, ${ }^{13}$ VSD closure, ${ }^{9}$ VSD closure and right ventricular outflow tract enlargement, ${ }^{24}$ pulmonary valvotomy and VSD closure, ${ }^{11}$ and subaortic membrane resection and VSD closure ${ }^{17}$ in one patient each. The surgical incisions were indicated in $15(15 / 19,78.9 \%)$ patients: $13(86.7 \%)$ patients were via a right ventriculotomy and $2(13.3 \%)$ were via a right atriotomy $\left(\chi^{2}=16.1\right.$, $\mathrm{p}<0.001)$.

Ozeke et al.22 reported managing their asymptomatic DCRV patient conservatively, but they did not specify the therapeutic agents.

The outcomes of 34 (54.8\%) patients were reported: 27 $(79.4 \%)$ patients were event-free survivors, $6(17.6 \%)$ patients had complications, and $1(2.9 \%)$ patient died. Of the 6 patients with complications, $4(66.7 \%)$ patients had postoperative complete atrioventricular block and $2(50 \%)$ of them required permanent pacemaker implant.4,8 One (16.7\%) patient had subacute constrictive pericarditis, which was cured by partial pericardiectomy and a 2-week prednisolone administration, 24 and 1 (16.7\%) patient developed postoperative transient blindness, which was significantly improved after conservative treatment. 10 There was no postoperative death.

The asymptomatic pateint with DCRV can be conservatively managed and followed up as indicated by Ozeke et al.22; however, they did not state the length of their follow-up on their patient. Thirteen $(21.0 \%)$ patients were on a postoperative follow-up ranging from 1-192 months.4,8,11,12 Postoperative intra-right ventricular pressure gradient was reported for 17 patients. It was detected by echocardiography in 11 patients, ,8,12,14,16 and the detection method was not specified for the remaining patients. The pressure gradient was significantly lower than the preoperative value $(92.8 \pm 27.6 \mathrm{mmHg}$ vs. $3.6 \pm 5.6$ $\mathrm{mmHg}, \mathrm{p}<0.001)$.

\section{DISCUSSION}

The etiology of obstruction was anomalous muscle bundles across the right ventricular cavity in 41 patients (67\%), right ventricular midventricular fibrous diaphragm in $19(31 \%)$ patients, hypertrophied moderator band in $5(8 \%)$ patients, and hypertrophied papillary muscle of the conus in $1(1.6 \%)$ patient. 25 Three levels of obstruction were present: low in $37(61 \%)$ patients, high in $14(23 \%)$ patients, and mixed level in $10(16 \%)$ patients. 25 The increased blood flow and pressure within the right ventricular outflow tract may act as an initial stimulus for hypertrophy of the crista supraventricularis in patients with VSD and notably increased pulmonary blood flow. ${ }^{5}$

Research on spatial relations between VSD and anomalous muscle band revealed that the VSD was proximal to the obstructing muscle bundle in 13 patients $(62 \%)$, and distal to the bundle in $8(38 \%) .15$ The pressure gradient within the right ventricle averaged $67 \mathrm{mmHg}$ in the proximal group and $83 \mathrm{mmHg}$ in the distal group. ${ }^{15}$ However, in literature, the relation between VSD and muscle band was not indicated in most instances. In some series, the VSD was noted to open to the proximal chamber in all cases; while in others, it opened to the distal chamber thus acting as an extension of the left ventricle.15 In general, VSD was proximal to the anomalous muscle band in $2 / 3$ cases. 15 The severity of right ventricular obstruction is progressive in some unoperated patients, with a speed of progression of $1.5-6 \mathrm{mmHg} /$ year. ${ }^{4}$ Progression of right ventricular obstruction can be due to muscle hypertrophy and/or endocardial fibrosis. ${ }^{4}$ No patient required reoperation for recurrence of intra-right ventricular obstruction, and no patient died during adulthood. ${ }^{4}$ The average peak pressure gradient across the VSD was $31 \mathrm{mmHg}$ when the VSD was proximal and $54 \mathrm{mmHg}$ when it was distal to the obstructing bundle. ${ }^{15}$

Obstructions of DCRV can be divided into three types: low and oblique obstruction, high and horizontal obstruction, and mixed obstruction. ${ }^{5}$ An angiographic study in 10 DCRV patients revealed an oblique and low 
obstruction in 6 patients and a high and horizontal obstruction in 4 patients. ${ }^{8}$ Hypertrophic septal and parietal muscle bundles might cause infundibular stenosis. 13

Alva et al. ${ }^{8}$ proposed certain criteria of diagnosis and surgical indications of DCRV. These include an intraright ventricular pressure gradient $>20 \mathrm{mmHg}$ by echocardiography or by cardiac catheterisation; an angiographic evidence of intra-right ventricular obstruction; normal right ventricular infundibulum; and surgical confirmation of DCRV during the operation. However, the criterium of "normal right ventricular infundibulum" could be suspicious, as it could be hypertrophied, narrowed, or thin-walled in DCRV patients, as shown in this report.

The presenting symptoms of patients with DCRV include syncope, angina, and severe dyspnea; clinically resembling pulmonary artery hypertension, ${ }^{2}$ and the high right ventricular systolic pressure is sometimes falsely interpreted as pulmonary artery hypertension. 26 Therefore, DCRV should be firstly differentiated with pulmonary artery hypertension. 27

DCRV can be misdiagnosed as VSD and lead to mistreatment.28 The mid-cavitary turbulent jet on transthoracic echocardiography can be mistaken as an intracardiac shunt, and thus, caution should be taken to differentiate DCRV from isolated VSD. 26 The subcostal view of transthoracic echocardiography (TTE) may sometimes provide better visualisation of the right ventricle and right ventricular outflow tract obstruction. 26 Moreover, it was once reported that 2 patients were reported development of DCRV 6-8 years after the surgical closure of VSD. 28

Anomalous muscle bundles in DCRV may cause right ventricular outflow tract obstruction. 29 Failure to detect the anomalous muscles in right ventricular cavity may lead to a misdiagnosis of severe right ventricular outflow obstruction and myocardial hypertrophy. Thus, it should be differentiated with other congenital heart defects causing right ventricular outflow tract obstruction, such as tetralogy of Fallot. Two dimensional echocardiography with Doppler flow analysis is useful in the evaluation and differential diagnosis of right ventricular outflow obstructions prior to invasive studies and surgical intervention. 30

Kahr et al. ${ }^{4}$ reported the follow-up results of 50 patients with DCRV. They found $47 \%$ of the patients were asymptomatic despite significant right ventricular obstruction, and $16 \%$ of these were completely asymptomatic during follow-up with conservative management. The remaining $42(84 \%)$ patients became symptomatic at a median age of 26 years. Out of these, $33(78.6 \%)$ patients were operated on and $91 \%$ of the operated patients showed no residual intra-ventricular gradient, and 27/33 of the patients had improved cardiac function. There was no early or late mortality and no re-intervention requirement for DCRV during a median follow-up of 8 years.

It has been suggested that the surgical resection of the anomalous muscle bundles should be performed once the diagnosis of DCRV is made. ${ }^{4}$ However, this approach is not popularly accepted. When the patient becomes symptomatic, or with progressive right ventricular outflow stenosis or progressive right ventricular inflow pressure overload, an early surgical repair is then warranted. Nevertheless, debates remain concerning the surgical indications for asymptomatic DCRV patients. ${ }^{1}$ It has been proposed that right ventricular outflow tract obstruction with a pressure gradient of 20$50 \mathrm{mmHg}$, detected by echocardiography or by cardiac catheterisation, is an indication for DCRV repair. ${ }^{4}$ Other authors have recommended close follow-up for patients with mild non-progressive intraventricular gradient without associated cardiac defects. 22 As it has been observed that sustained monomorphic ventricular tachycardia in patients with unoperated DCRV was resolved after surgical removal of the obstructing muscular bundles; therefore, a surgical treatment of DCRV is indicated for the patients with evidence of ventricular tachycardia. 4

Kahr et al. 4 reported that DCRV repair was carried out via a median sternotomy in all their patients, in whom a right ventriculotomy was used in $36 \%$ patients, a combined right atriotomy and right ventriculotomy in $32 \%$, a pulmonary arteriotomy in $23 \%$, and a transatrial approach in $9 \%$ of the patients. Right ventriculotomy was generally avoided in patients operated after 2001 due to the concern of right ventricular function depression and ventricular tachycardia secondary to right ventriculotomy. ${ }^{4}$ Nevertheless, in adult patients with advanced obstruction and a high right ventricular outflow pressure gradient, a right ventriculotomy is sometimes warranted for the relief of obstruction. 1

Ozeke et al. 22 reported briefly to manage their asymptomatic DCRV patient conservatively, but they did not specify the therapeutic drugs. No other authors adopted conservative treatment for DCRV patients. By searching the literature, it was found that none described the use of $\beta$-blockade and calcium channel blockade in either pediatric or adult patients with DCRV.

DCRV has a favourable postoperative course and no postoperative death was reported. The likelihood of DCRV recurrence is very low; however, postoperative follow-up was always less than 10 years in most series. 1

\section{CONCLUSION}

A DCRV is a rare congenital heart defect. Most of the patients are symptomatic with signs of right ventricular pressure overload and are associated with other congenital heart defects, especially perimembranous VSDs. The spatial relation between VSD and the 
anomalous muscle bundle might be a determinant of right ventricular obstruction. Symptomatic patients with an intra-right ventricular pressure gradient of $>20 \mathrm{mmHg}$ are indicated for a surgical repair. DCRV has a favourable postoperative course as no postoperative death was reported. Mechanisms of right ventricular obstruction warrant further elucidations based on large patient population in the near future.

\section{ETHICAL APPROVAL:}

Ethical approvals were obtained from the Institutional Review Board prior to initiation of the research work.

\section{CONFLICT OF INTEREST:}

The author declares no conflict of interest.

\section{AUTHORS' CONTRIBUTION:}

SMY: Substantial contribution to the conception and design of the work; and the acquisition, analysis, and interpretation of data for the work; drafting the work and revising it critically for important intellectual content; final approval of the version to be published; agreement to be accountable for all aspects of the work in ensuring that questions related to the accuracy and integrity of any part of the work are appropriately investigated and resolved.

\section{REFERENCES}

1. Amano M, Izumi C, Hayama $\mathrm{Y}$, Onishi N, Tamaki $\mathrm{Y}$, Enomoto $\mathrm{S}$, et al. Surgical outcomes and postoperative prognosis beyond 10 years for double-chambered right ventricle. Am J Cardiol 2015; 116:1431-5.

2. McElhinney DB, Chatterjee KM, Reddy VM. Double-chambered right ventricle presenting in adulthood. Ann Thorac Surg 2000; 70:124-7.

3. Cil E, Saraçlar M, Ozkutlu S, Ozme S, Bilgiç A, Ozer S, et al. Double-chambered right ventricle: experience with 52 cases. Int J Cardiol 1995; 50:19-29.

4. Kahr PC, Alonso-Gonzalez R, Kempny A, Orwat S, Uebing A, Dimopoulos $\mathrm{K}$, et al. Long-term natural history and postoperative outcome of double-chambered right ventricle-experience from two tertiary adult congenital heart centres and review of the literature. Int J Cardiol 2014; 174:662-8.

5. Hoffman P, Wójcik AW, Rózanski J, Siudalska H, Jakubowska E, Wlodarska EK, et al. The role of echocardiography in diagnosing double chambered right ventricle in adults. Heart 2004; 90:789-93.

6. Yuan SM. Congenital heart defects in Williams syndrome. Turk J Pediatr 2017; 59:225-232.

7. Oliver JM, Garrido A, González A, Benito F, Mateos M, Aroca A, et al. Rapid progression of midventricular obstruction in adults with double-chambered right ventricle. J Thorac Cardiovasc Surg 2003; 126:711-7.

8. Alva C, Ortegón J, Herrera F, Meléndez C, David F, Jiménez S, et al. Types of obstructions in double-chambered right ventricle: mid-term results. Arch Med Res 2002; 33:261-4.
9. Animasahun BA, Ekure EN, Njokanma OF. Double-chambered right ventricle: An uncommon congenital heart disease. Case report and literature review. Cardiovasc J Afr 2011; 22:274-7.

10. Atik E, Cavalini JF. Case 4/2017 - Double-chambered right ventricle with dextrocardia and hypoxemia due to atrial shunt in a 4-year-old girl. Arq Bras Cardiol 2017; 108:569-571.

11. Bharati S, Sharma MK, Chattopadhay A, Das D. Transient cortical blindness following intracardiac repair of congenital heart disease in an 11-year-old boy. Ann Card Anaesth 2017; 20:256-8.

12. Ceyran H, Narin N, Tasdemir K, Tevfik T, Emirogullari ON, Akçakus M. Double-chambered right ventricle mimicking asymmetric septal hypertrophy. Turk J Pediatr 2003; 45:80-2.

13. Chaurasia AS, Nawale JM, Yemul MA. Double-chambered right ventricle with pulmonary valve endocarditis. Echocardiography 2013; 30:E167-70.

14. El Kouache M, Babakhoya A, Labib S, El Madi A, Atmani S, Harandou $\mathrm{M}$, et al. Repair of isolated double-chambered right ventricle. Afr J Paediatr Surg 2013; 10:199-200.

15. Hubail ZJ, Ramaciotti C. Spatial relationship between the ventricular septal defect and the anomalous muscle bundle in a double-chambered right ventricle. Congenit Heart Dis 2007; 2:421-3.

16. Kardux JJ, van Es HW, Rensing BJ. Case 119: Doublechambered right ventricle. Radiology 2007; 244:617-9.

17. Kharwar RB, Dwivedi SK, Sharma A. Double-chambered right ventricle with ventricular septal defect and subaortic membrane - three-dimensional echocardiographic evaluation. Echocardiography 2016; 33:323-7.

18. Knerr I, Zschocke J, Schellmoser S, Topf HG, Weigel C, Dötsch J, et al. An exceptional Albanian family with seven children presenting with dysmorphic features and mental retardation: maternal phenylketonuria. BMC Pediatr 2005; 5:5.

19. Marton T, Hajdú J, Papp Z. A rare case of non-immune hydrops fetalis: Double-chambered right ventricle. A case report. Fetal Diagn Ther 2001; 16:251-3.

20. Masci PG, Gewillig M, Bogaert J. Double-chambered right ventricle. Eur Heart J 2007; 28:2237.

21. Otto RK, Ferguson MR. Right ventricular apical sequestration: Demonstration of a rare variant of double-chambered right ventricle with MRI. Pediatr Radiol 2013; 43:634-6.

22. Ozeke O, Sahin O, Tufekcioglu O, Aras D, Geyik B. Doublechambered right ventricle associated with membranous interventricular septal aneurysm. Eur J Echocardiogr 2004; 5:453-4.

23. Puvaneswary M, Indira N, Sreedhar M, Barooah B. Doublechambered right ventricle: Magnetic resonance imaging findings. Australas Radiol 2005; 49:170-4.

24. Tanaka K, Kawauchi M, Murota Y, Takamoto I, Ikenouchi H, Hada $\mathrm{Y}$, et al. Reversible subacute effusive-constrictive pericarditis after correction of double-chambered right ventricle: A case report. J Cardiol 2002; 39:267-70.

25. Said SM, Burkhart HM, Dearani JA, O'Leary PW, Ammash NM, Schaff HV. Outcomes of surgical repair of double-chambered right ventricle. Ann Thorac Surg 2012; 93:197-200.

26. Lee JK, Tsui KL. Double-chambered right ventricle: A commonly overlooked diagnosis. Hong Kong Med J 2015; 21:84.e1-2. 
27. Adjagba PM, Sonou A, Tossa LB, Codjo L, Hounkponou M, Moutaïrou SA, et al. Isolated double-chambered right ventricle (DCRV): A case study conducted at the National University Hospital CNHU-HKM in Cotonou, Benin. Pan Afr Med J 2017; 27:7.

28. Telagh R, Alexi-Meskishvili $\mathrm{V}$, Hetzer R, Lange PE, Berger F, Abdul-Khaliq $\mathrm{H}$. Initial clinical manifestations and mid- and long-term results after surgical repair of double-chambered right ventricle in children and adults. Cardiol Young 2008; 18: 268-74.

29. Mohsen A, Rahman F, Ikram S. Anomalous muscle bundles causing double-chambered right ventricle in adults. J Invasive Cardiol 2013; 25:E212-3.

30. Joy MV, Subramonium R, Venkitachalam CG, Balakrishnan KG. Two dimensional and doppler echocardiographic evaluation of double chambered right ventricle. Indian Heart J 1992; 44:159-63.

.......... 